\title{
Altered Innate Immune Responses in Neutrophils from Patients with Well- and Suboptimally Controlled Asthma
}

\author{
Francesca S. M. Tang, ${ }^{1,2}$ Gloria J. Foxley, ${ }^{1}$ Peter G. Gibson, ${ }^{3}$ Janette K. Burgess, ${ }^{1,2,4}$ \\ Katherine J. Baines, ${ }^{3}$ and Brian G. Oliver ${ }^{1,5}$ \\ ${ }^{1}$ Woolcock Institute of Medical Research, The University of Sydney, Sydney, NSW 2006, Australia \\ ${ }^{2}$ Discipline of Pharmacology, School of Medical Sciences, Faculty of Medicine, The University of Sydney, Sydney, NSW 2006, Australia \\ ${ }^{3}$ Priority Research Centre for Asthma and Respiratory Disease, The University of Newcastle, Newcastle, NSW 2308, Australia \\ ${ }^{4}$ Department of Pathology and Medical Biology, University of Groningen, University Medical Centre Groningen, \\ 9713GZ Groningen, Netherlands \\ ${ }^{5}$ School of Life Sciences, University of Technology Sydney, Sydney, NSW 2007, Australia
}

Correspondence should be addressed to Francesca S. M. Tang; ftan8512@uni.sydney.edu.au

Received 19 August 2015; Revised 22 October 2015; Accepted 26 October 2015

Academic Editor: Kang-Yun Lee

Copyright (C) 2015 Francesca S. M. Tang et al. This is an open access article distributed under the Creative Commons Attribution License, which permits unrestricted use, distribution, and reproduction in any medium, provided the original work is properly cited.

\begin{abstract}
Background. Respiratory infections are a major cause of asthma exacerbations where neutrophilic inflammation dominates and is associated with steroid refractory asthma. Structural airway cells in asthma differ from nonasthmatics; however it is unknown if neutrophils differ. We investigated neutrophil immune responses in patients who have good $\left(\mathrm{A}_{\mathrm{Good}}\right)$ and suboptimal $\left(\mathrm{A}_{\text {Subopt }}\right)$ asthma symptom control. Methods. Peripheral blood neutrophils from $\mathrm{A}_{\text {Good }}$ (ACQ $\left.<0.75, n=11\right), \mathrm{A}_{\text {Subopt }}(\mathrm{ACQ}>0.75, n=7)$, and healthy controls (HC) $(n=9)$ were stimulated with bacterial (LPS $(1 \mu \mathrm{g} / \mathrm{mL}), \mathrm{fMLF}(100 \mathrm{nM}))$, and viral (imiquimod $(3 \mu \mathrm{g} / \mathrm{mL})$, R848 $(1.5 \mu \mathrm{g} / \mathrm{mL})$, and poly I:C $(10 \mu \mathrm{g} / \mathrm{mL}))$ surrogates or live rhinovirus (RV) 16 (MOI1). Cell-free supernatant was collected after $1 \mathrm{~h}$ for neutrophil elastase (NE) and matrix metalloproteinase- (MMP-) 9 measurements or after $24 \mathrm{~h}$ for CXCL8 release. Results. Constitutive NE was enhanced in $\mathrm{A}_{\text {Good }}$ neutrophils compared to HC. fMLF stimulated neutrophils from $\mathrm{A}_{\text {Subopt }}$ but not $\mathrm{A}_{\text {Good }}$ produced $50 \%$ of HC levels. fMLF induced MMP-9 was impaired in $\mathrm{A}_{\text {Subopt }}$ and $\mathrm{A}_{\text {Good }}$ compared to HC. fMLF stimulated CXCL8 but not MMP-9 was positively correlated with $\mathrm{FEV}_{1}$ and $\mathrm{FEV}_{1} / \mathrm{FVC}$. $\mathrm{A}_{\text {Subopt }}$ and $\mathrm{A}_{\mathrm{Good}}$ responded similarly to other stimuli. Conclusions. Circulating neutrophils are different in asthma; however, this is likely to be related to airflow limitation rather than asthma control.
\end{abstract}

\section{Introduction}

Mainstay therapy for asthma is a combination of a long-acting $\beta_{2}$ agonist to relax smooth muscle in the airways and a corticosteroid to reduce inflammation in the lungs [1]. However, even at high doses of these medications some patients remain unresponsive. These patients with uncontrolled or difficult to treat asthma often have a neutrophilic phenotype $[2,3]$; however a group of patients with a steroid refractory eosinophilic phenotype also exist $[4,5]$. These patients not only are unable to obtain symptom relief but also suffer from more frequent and severe exacerbations $[6,7]$.

Asthma exacerbations may be triggered by a number of provokers of which the most common are respiratory infections. Viral infections have been extensively studied and rhinovirus (RV) is the most commonly detected virus in exacerbating adults [8]. Bacterial infections are not as rigorously examined but appear to also be clinically significant [9] . Respiratory infections pose a high threat to patients suffering from uncontrolled asthma as they can trigger exacerbations that are often severe and leave the patient hospitalised with limited treatment options [10, 11].

Neutrophils are the most abundant immune cell in the body; their main effector role is to control infections. CXCL8 is a potent neutrophil chemoattractant, neutrophil elastase (NE) has potent antimicrobial properties, and matrix metalloproteinase- (MMP-) 9 is important in activating antimicrobial peptides, all of which are released by neutrophils. 
TABLE 1: Patient characteristics of healthy controls and asthmatics.

\begin{tabular}{lccc}
\hline & Healthy controls & Asthma, well-controlled & Asthma, suboptimally controlled \\
\hline$N$ & 9 & 11 & 7 \\
Age years, mean $( \pm$ SEM $)$ & $60.22( \pm 5.12)$ & $62.64( \pm 3.97)$ & $62.57( \pm 4.02)$ \\
Gender $(\mathrm{M} / \mathrm{F})$ & $6 / 3$ & $7 / 4$ & $5 / 2$ \\
$\mathrm{ACQ}$, mean $( \pm \mathrm{SEM})$ & $0( \pm 0)$ & $0.32( \pm 0.08)^{*}$ & $1.33( \pm 0.17)^{* * * * / \# \# \#}$ \\
$\mathrm{FEV}_{1} \%$ pred. $( \pm \mathrm{SEM})$ & $92.78( \pm 5.98)$ & $88.36( \pm 4.51)^{*}$ & $70.29( \pm 8.09)$ \\
$\mathrm{FEV}_{1} / \mathrm{FVC} \%$ pred. $( \pm \mathrm{SEM})$ & $101.8( \pm 1.65)$ & $9 / 0$ & $77.43( \pm 5.27)^{* *}$ \\
Short-acting $\beta_{2}$ agonist use $(\mathrm{Y} / \mathrm{N})$ & $0 / 9$ & $7 / 0$ \\
\hline
\end{tabular}

${ }^{*} p<0.05,{ }^{* *} p<0.01$, and ${ }^{* * * *} p<0.0001$ compared to healthy controls.

$\# \#$ \#\#\# $p<0.0001$ compared to patients with asthma with good symptom control.

ACQ: asthma control questionnaire.

$\mathrm{FEV}_{1}$ : forced expiratory volume in 1 second.

FVC: forced vital capacity.

Transient neutrophilia and neutrophilic inflammation are a normal phase of the immune response to pathogens [12]; however, chronic airway inflammation occurs in stable asthma $[2,13,14]$. In a study of 205 patients, multivariate linear regression has shown no association of airway neutrophilia with corticosteroid use [15], and airway neutrophilia occurs in asthmatic patients who are corticosteroid naïve [16]. In addition, neutrophil numbers [2] and neutrophil inflammatory mediators such as CXCL8 [17], NE [18], and MMP-9 [19] are elevated in the airways of patients with severe asthma and these levels correlate with disease severity $[2,20]$.

It has been shown that structural cells, such as epithelial and smooth muscle cells, in the asthmatic airway are different compared to nonasthmatic cells in both morphology and function [21-24]. It is believed that these functional abnormalities drive other changes in the airways which give rise to the hallmarks of asthma. We previously found that circulating neutrophils from patients with asthma are altered in their response to the viral mimetic, R848 by producing elevated levels of CXCL8 [25], and expression quantitative trait loci mapping in neutrophils has found immune dysfunction trait associated variants [26]. However, to date it has not been investigated if neutrophil functions differ in patients with suboptimal symptom control despite taking moderate to high dose steroid therapy. Neutrophil dysfunction may occur in these patients which would, in part, account for the greater inflammatory mediator load in this group of patients.

Neutrophils are produced in the bone marrow and have a relatively short life span $[27,28]$. Given our previous finding of different responses of lung versus circulating neutrophils [29], to ascertain if neutrophils are already different prior to entering the lung in well- and suboptimally controlled asthma we compared the response to both bacterial and viral mimetics in circulating neutrophils to avoid any potential confounding effects of the lung inflammatory environment. We hypothesised that neutrophils from patients with suboptimally controlled asthma have a defective innate immunity which may predispose to pathogen-induced exacerbations.

\section{Materials and Methods}

2.1. Volunteer Recruitment. The project was approved by the Human Research Ethics Committee, The University of
Sydney, prior to commencement. Volunteers with doctor diagnosed asthma, stable disease, and no reported symptoms of respiratory infection were recruited into the study. Healthy control volunteers were also recruited. Participants were required to be over 18 years of age and be fluent in English. Exclusion criteria included if they were pregnant, were known to faint during venipuncture procedures, or had a blood borne infection or condition. All volunteers provided written informed consent and were asked to complete a standardised questionnaire regarding age, gender, asthma symptoms, asthma medication use, and smoking history. Patients also completed baseline spirometry for forced expiratory volume in 1 second $\left(\mathrm{FEV}_{1}\right)$ and forced vital capacity (FVC). Participants with asthma were asked to withhold their short-acting $\beta_{2}$ agonists for a minimum of 6 hours and 24 hours for long-acting $\beta_{2}$ agonists and inhaled corticosteroids (ICS).

2.2. Categorisation of Asthmatics. Participants with asthma were stratified based on their asthma control questionnaire (ACQ) score [30]. A cut point of ACQ $<0.75$ was used to identify well-controlled asthma [30]. Participants with suboptimal asthma control (ACQ $\geq 0.75$ ) also had evidence of variable airflow limitation $\left(\mathrm{PD}_{15}<15 \mathrm{~mL}\right.$ hypertonic saline or standard challenge agent, change in postbronchodilator $\mathrm{FEV}_{1}>12 \%$ of $200 \mathrm{~mL},>12 \%$ peak flow variability over at least 1 week, or $\mathrm{FEV}_{1}$ variability $>12 \%$ of two measurements within two months of each other) and were taking a minimum of GINA step 3 maintenance combination therapy. Patient information is provided in Tables 1 and 2.

2.3. Neutrophil Isolation. Neutrophils were isolated from peripheral blood collected from volunteers with and without asthma by a modified standard protocol [29, 31, 32]. Briefly, $40 \mathrm{~mL}$ of blood was mixed with $10 \mathrm{~mL}$ acid citrate dextrose (ACD), $10 \mathrm{~mL}$ of phosphate buffered saline (PBS) (Gibco, Carlsbad, CA, USA), and $6 \mathrm{~mL}$ of $10 \%$ dextran (MP Biomedicals, Santa Ana, USA) and left for 20 minutes for sedimentation to occur at room temperature. The top layer was removed, overlaid on Ficoll Paque-PLUS (GE Healthcare, Little Chalfont, UK), and centrifuged at $490 \mathrm{~g}$ for 10 minutes. 
TABLE 2: Smoking history and inhaled corticosteroid (ICS) use of healthy controls and asthmatics.

(a)

\begin{tabular}{lccc}
\hline \multicolumn{3}{c}{ Healthy controls } & \\
Age & Sex & Smoking status & Pack years \\
\hline 66 & Male & Nonsmoker & 0 \\
66 & Male & Nonsmoker & 0 \\
62 & Female & Ex-smoker & 15 \\
70 & Male & Nonsmoker & 0 \\
63 & Female & Nonsmoker & 0 \\
67 & Male & Nonsmoker & 0 \\
61 & Female & Nonsmoker & 0 \\
67 & Male & Nonsmoker & 0 \\
20 & Male & Nonsmoker & 0 \\
\hline
\end{tabular}

(b)

\begin{tabular}{|c|c|c|c|c|c|c|}
\hline \multicolumn{7}{|c|}{ Asthma, well-controlled ${ }^{*}$} \\
\hline Age & Sex & Smoking status & Pack years & $\begin{array}{l}\text { Daily ICS BDP-HFA } \\
\text { equivalent ( } \mu \mathrm{g} / \text { day })\end{array}$ & \multicolumn{2}{|c|}{ ICS in last 12 months in BDP-HFA equivalent ( $\mu \mathrm{g} /$ day) } \\
\hline 69 & Female & Nonsmoker & 0 & 0 & \multicolumn{2}{|c|}{200 (during exacerbations) } \\
\hline 71 & Male & Ex-smoker & 18 & 200 & \multicolumn{2}{|l|}{-} \\
\hline 75 & Male & Nonsmoker & 0 & 0 & \multicolumn{2}{|l|}{-} \\
\hline 63 & Male & Ex-smoker & 0.5 & 1000 & \multicolumn{2}{|c|}{2000 (when needed) } \\
\hline 52 & Male & Nonsmoker & 0 & 0 & \multicolumn{2}{|c|}{$200^{\dagger}$ (exercise only) } \\
\hline 61 & Female & Nonsmoker & 0 & 0 & \multicolumn{2}{|c|}{200 (in the last 12 months, ceased 3 months ago) } \\
\hline 63 & Male & Current smoker & 43 & 0 & \multicolumn{2}{|c|}{200 (in high humidity, not used in the past months) } \\
\hline 73 & Male & Ex-smoker & 21 & 1000 & \multicolumn{2}{|l|}{-} \\
\hline 28 & Male & Nonsmoker & 0 & 125 & \multicolumn{2}{|l|}{-} \\
\hline 69 & Female & Nonsmoker & 0 & $100^{\dagger}$ & \multicolumn{2}{|l|}{$200^{\dagger}$ (when sick) } \\
\hline 65 & Female & Nonsmoker & 0 & 250 & \multicolumn{2}{|l|}{500 (when sick) } \\
\hline \multicolumn{7}{|c|}{ (c) } \\
\hline \multicolumn{7}{|c|}{ Asthma, suboptimally controlled* } \\
\hline Age & Sex & Smoking status & Pack years & \multicolumn{2}{|c|}{ Daily ICS BDP-HFA equivalent ( $\mu \mathrm{g} /$ day) } & Oral steroid use in last 12 months \\
\hline 62 & Male & Ex-smoker & 0.2 & \multicolumn{2}{|c|}{800} & Yes \\
\hline 71 & Female & Ex-smoker & 0.6 & \multicolumn{2}{|c|}{400} & Yes \\
\hline 74 & Male & Ex-smoker & 4.5 & \multicolumn{2}{|c|}{1000} & No \\
\hline 47 & Male & Nonsmoker & 0 & \multicolumn{2}{|c|}{1000} & No \\
\hline 73 & Female & Nonsmoker & 0 & \multicolumn{2}{|c|}{1000} & Yes \\
\hline 52 & Male & Ex-smoker & 7.15 & \multicolumn{2}{|c|}{200} & No \\
\hline 59 & Male & Nonsmoker & 0 & 50 & & No \\
\hline
\end{tabular}

${ }^{*}$ See Section 2 for inclusion criteria.

${ }^{\dagger}$ ICS-only inhaler; all other patients using ICS/LABA consistent with Australian prescribing trends [37].

BDP-HFA: beclometasone dipropionate (hydrofluoroalkane propellant).

ICS: inhaled corticosteroid.

The supernatant was discarded and the cell pellet of granulocytes was resuspended in sterile water for 30 seconds to lyse remaining red blood cells before osmolarity was reestablished with equal parts of $2 \mathrm{x}$ PBS. Cells were then incubated for 30 minutes at $4^{\circ} \mathrm{C}$ with CD16 magnetic beads (Miltenyi Biotec, Bergisch, Germany) before running through a magnetic column as per the manufacturer's instructions. Previous optimisation of the protocol showed typical purity was $99 \%$ or greater by a haematoxylin and eosin stain. The main contaminating cell was eosinophils $(<1 \%)$.

2.4. RV16. RV16 was generously donated by Professor Sebastian Johnston, Imperial College, London, UK. RV16 was grown in HeLa cells by standard procedures and infectivity titre determined by a titration assay as described [33]. 
2.5. Stimulation of Neutrophils with Toll-Like Receptor (TLR) Agonists and RV16. Neutrophils were resuspended in 1\% fetal bovine serum (FBS) (Glendarach Biologicals, Melbourne, Australia), 1\% 1M HEPES (Gibco), and 1\% penicillin/streptomycin RPMI 1640 (Gibco) at $1 \times 10^{6}$ cells $/ \mathrm{mL}$. Cells were left unstimulated (negative control) or stimulated with $\mathrm{EC}_{50}$ concentrations of each TLR agonist based on dose-response curves generated for CXCL8 release (data not shown): $1 \mu \mathrm{g} / \mathrm{mL}$ LPS (Sigma Aldrich, St. Louis, MO, USA), $3 \mu \mathrm{g} / \mathrm{mL}$ imiquimod (Invivogen, San Diego, USA), $1.5 \mu \mathrm{g} / \mathrm{mL}$ R848 (Invivogen), and $10 \mu \mathrm{g} / \mathrm{mL}$ poly I:C (Sigma Aldrich), except fMLF (Sigma Aldrich) (100 nM) which was based on previous reports [34]. Neutrophils were also stimulated with RV16 at a multiplicity of infection (MOI) of 1 infectious particle per cell as previously published $[25,35]$. Cells were incubated at $37^{\circ} \mathrm{C}$ with $5 \% \mathrm{CO}_{2}$ for 1 hour for NE and MMP9 measurements or 24 hours for CXCL8 measurements. Cellfree supernatant and neutrophils cell pellets were collected and stored at $-80^{\circ} \mathrm{C}$ for analysis.

2.6. CXCL8 Enzyme-Linked Immunosorbent Assay (ELISA). CXCL8 production was measured using a sandwich ELISA in duplicate. Specific ELISA kits from R\&D Systems (Minneapolis, USA) were used according to the manufacturer's instructions. Detection limit was $15.6 \mathrm{pg} / \mathrm{mL}$.

2.7. Neutrophil Elastase (NE) Activity Assay. NE activity was measured in duplicate using a fluorescence assay from Cayman Chemicals (Ann-Arbor, USA) according to the manufacturer's instructions. Fluorescence readings from samples were compared to a standard curve of known concentrations of NE to determine the concentration. Detection limit was $3.1 \mathrm{ng} / \mathrm{mL}$.

2.8. MMP-9 Zymography. A bicinchoninic acid assay (Sigma Aldrich) was run for all samples according to the manufacturer's instructions to obtain the total protein concentration. Zymography was carried out according to previously published methods [36]. Briefly, $200 \mathrm{ng}$ of total protein was loaded into each lane of a $1 \%$ gelatin polyacrylamide gel. The gel was run and then proteinases were activated in a $\mathrm{CaCl}_{2}$ activation buffer overnight before staining with Coomassie brilliant blue dye. Bands were determined to be pro-MMP-9 using size markers and MMP-9 standards. Densitometry was performed with Carestream Molecular Imaging Software on images taken on a Kodak Image Station from Integrated Sciences (Chatswood, Australia) to determine the relative fold change compared to media control.

2.9. Data and Statistical Analysis. For statistical analysis, data was normalised $\left(\log _{10}\right)$ before normality tests were conducted (Kolmogorov-Smirnov, D'Agostino and Pearson, and Shapiro-Wilk normality tests; GraphPad Prism 6). They were deemed to have a normal distribution if they passed one of the three normality tests. A paired $t$-test or one-way analysis of variance (ANOVA) with Dunnett's posttest was performed if the data followed a normal distribution or a Wilcoxon matched $t$-test or Friedman test with Dunn's multiple comparison test if data were nonparametric. Twoway ANOVA with Tukey's posttest was performed for comparisons between healthy controls, well-controlled asthmatic, and suboptimally controlled asthmatic. For some data sets, correlation analysis was performed. Significant changes were identified where $p<0.05$.

\section{Results}

3.1. Patient Characteristics. The clinical characteristics for the study population are detailed in Tables 1 and 2. Patients were all age and gender matched with the mean age of approximately 60 years and each group consisted predominately of males. By definition, mean ACQ was different between the two asthma groups (good symptom control: mean 0.32, suboptimal symptom control: mean 1.33) There were no differences in $\mathrm{FEV}_{1} \%$ predicted between the three patient groups; however $\mathrm{FEV}_{1} / \mathrm{FVC} \%$ ratio was significantly less in patients with well-controlled and suboptimally controlled asthma compared to healthy controls (Table 1). The majority of participants with well-controlled asthma were taking a short-acting $\beta_{2}$ agonist (82\%) (Table 1) with only 55\% taking an ICS containing inhaler daily (Table 2). However, all but 1 patient in this group took combination therapy intermittently in the past 12 months (Table 2). All participants with suboptimal asthma symptom control were taking a short-acting $\beta_{2}$ agonist (Table 1) along with combination therapy (Table 2).

3.2. Differential CXCL8 Release from Neutrophils from Asthmatics. All bacterial and viral mimetics including LPS, fMLF, imiquimod, R848, and poly I:C induced significant CXCL8 release from neutrophils isolated from healthy controls and well-controlled and suboptimally controlled asthmatics (Figures 1(a) and 1(b)). Interestingly, RV16 induced CXCL8 only in neutrophils from well-controlled and suboptimally controlled asthmatics (Figure 1(c)). Neutrophils from suboptimally controlled asthmatics had a deficient CXCL8 response to fMLF of approximately half when compared to healthy controls (Figure 1(a)). There was also a trend for neutrophils derived from well-controlled asthmatics to release less CXCL8 in response to fMLF which was of similar magnitude to neutrophils from suboptimally controlled asthmatics (Figure 1(a)). All other stimulants induced similar production of CXCL8 between all three groups.

\subsection{Differential NE Release from Neutrophils from Asthmatics.} fMLF was the only pathogen mimetic to induce NE from neutrophils in all three groups (Figure 2(a)). Interestingly, we found that, at baseline, neutrophils from well-controlled asthmatics had enhanced NE release compared to healthy controls (Figure 2(a)). Furthermore, this difference was also found when stimulated with fMLF (Figure 2(a)). RV16 did not induce NE release from neutrophils in any of the three groups.

3.4. Differential MMP-9 Release from Neutrophils from Asthmatics. LPS, fMLF, and imiquimod induced MMP-9 release from neutrophils in all three groups (Figures 3(a) and 3(b)). 


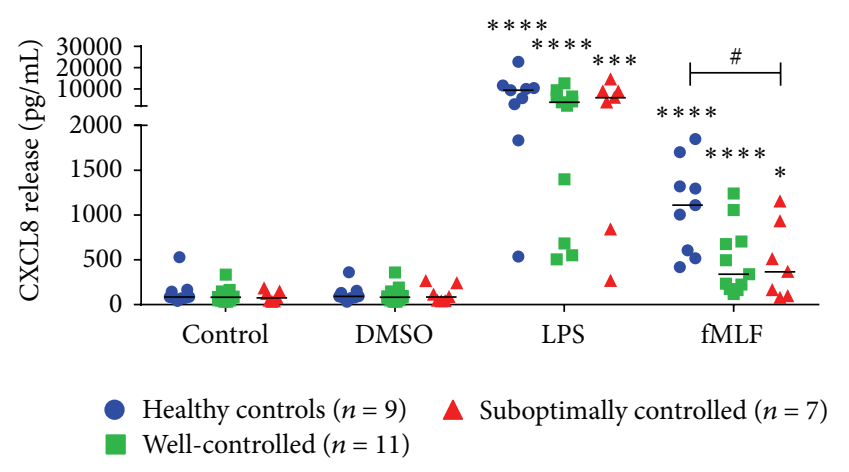

(a)

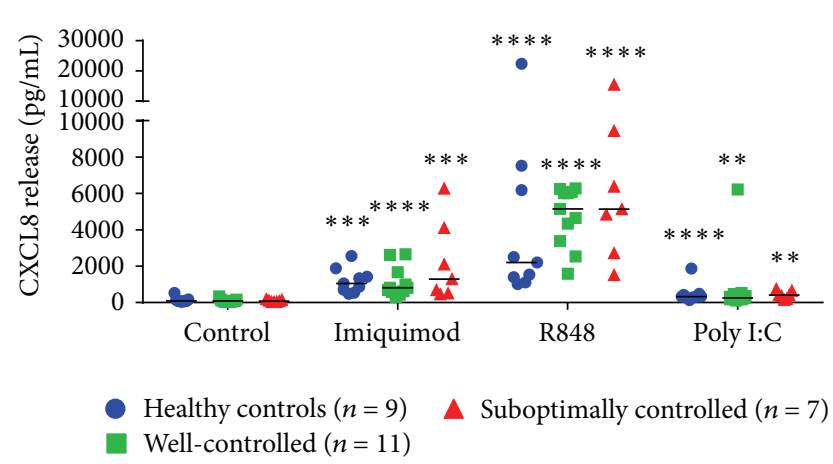

(b)

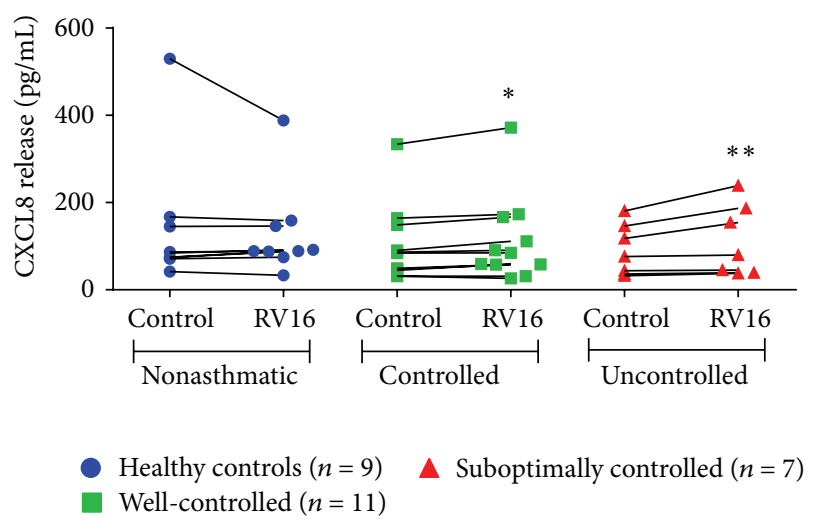

(c)

FIGURE 1: CXCL8 release from neutrophils stimulated with bacterial and viral mimetics and RV16. CXCL8 release from healthy controls (blue circles, $n=9$ ), well-controlled asthmatic (green squares, $n=11$ ), and suboptimally controlled asthmatic (red triangles, $n=7)$ neutrophils stimulated with (a) bacterial compounds: lipopolysaccharide (LPS), f-Met-Leu-Phe (fMLF), and DMSO (vehicle control), (b) viral surrogates: imiquimod, R848, and polyinosinic:polycytidylic acid (poly I:C), and (c) RV16 after 24 hours. Raw data is presented as a scatter plot with median. ${ }^{*} p<0.05,{ }^{* *} p<0.01,{ }^{* * *} p<0.001$, and ${ }^{* * * *} p<0.0001$ compared to unstimulated control. ${ }^{*} p<0.05$ between indicated groups.

Similar to CXCL8 data, fMLF stimulated neutrophils from well-controlled and suboptimally controlled asthmatics had a deficient MMP-9 response compared to healthy controls (Figure 3(a)). Interestingly, R848 selectively induced MMP9 in neutrophils derived from well-controlled and suboptimally controlled asthmatics, but not in healthy controls (Figure 3(b)). RV16 did not induce MMP-9 release from neutrophils in any of the three groups investigated.

\section{5. $F E V_{1} \%$ Predicted and $F E V_{1} / F V C \%$ Ratio Correlated with} fMLF Induced CXCL8. To further investigate if the differences in PMLF induced CXCL8 and MMP-9 in controlled and uncontrolled asthmatics were related to airway obstruction, we performed correlation analysis. We found that $\mathrm{FEV}_{1} \%$ predicted and $\mathrm{FEV}_{1} / \mathrm{FVC} \%$ ratio positively correlated with fMLF induced CXCL8 release (Figures 4(a) and 4(b)) but not fMLF induced MMP-9 release (Figures 4(c) and 4(d)). There was no correlation between ACQ and AMLF induced CXCL8 $(r=-0.318,0.106)$ or MMP-9 $(r=-0.181, p=$ $0.367)$. No correlations were found between pack year history and fMLF induced CXCL8 $(r=-0.04, p=0.84)$ or basal CXCL8 $(r=-0.07, p=0.74)$. Similarly, no correlations were found between daily ICS dose and AMLF induced CXCL8 $(r=-0.15, p=0.45)$ or basal CXCL8 $(r=0.12, p=0.55)$.
We also found no correlation between basal CXCL8 release and $\mathrm{FEV}_{1} \%$ predicted $(r=0.028, p=0.889)$ or $\mathrm{FEV}_{1} / \mathrm{FVC} \%$ ratio $(r=0.029, p=0.884)$.

\section{Discussion}

In this study we found that neutrophils from patients with asthma respond differently to fMLF compared to healthy controls. However, we did not see differences between neutrophils from patients with well- versus suboptimally controlled asthma. RV16 induced CXCL8 and R848 induced MMP-9 occurred in only neutrophils from well- and suboptimally controlled asthmatic groups but not in neutrophils from healthy controls. fMLF stimulation resulted in a deficient MMP-9 production in neutrophils from well-controlled asthmatics and a deficient CXCL8 and MMP-9 in suboptimally controlled asthmatics. In addition, NE was differentially regulated and was constitutively elevated in wellcontrolled asthmatics. This increased constitutive release most likely accounts for the difference observed in fMLF stimulated neutrophils from well-controlled asthmatics. We also found that PMLF induced CXCL8 and MMP-9 release correlated with lung function but not ACQ, smoking history, or ICS use. 


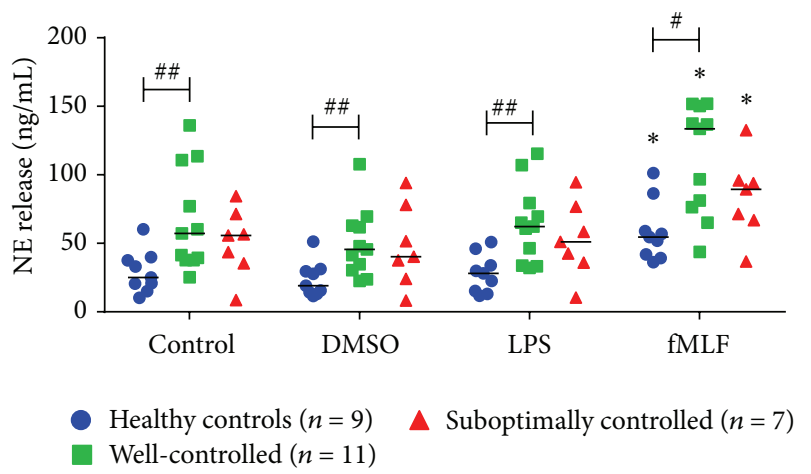

(a)

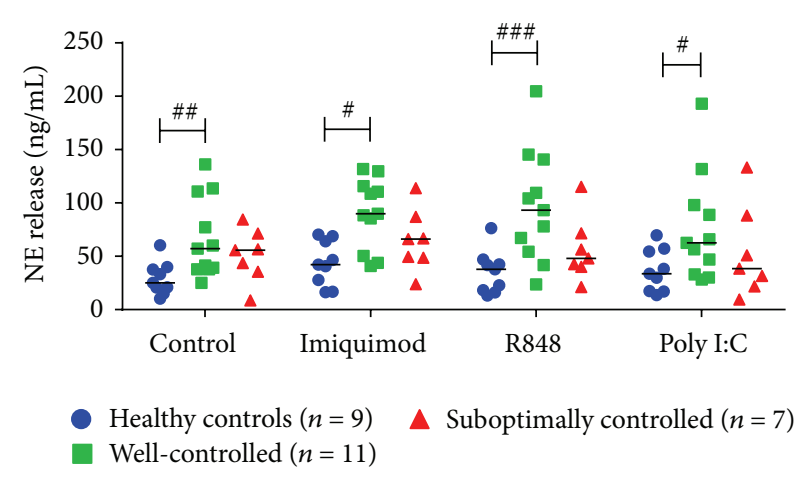

(b)

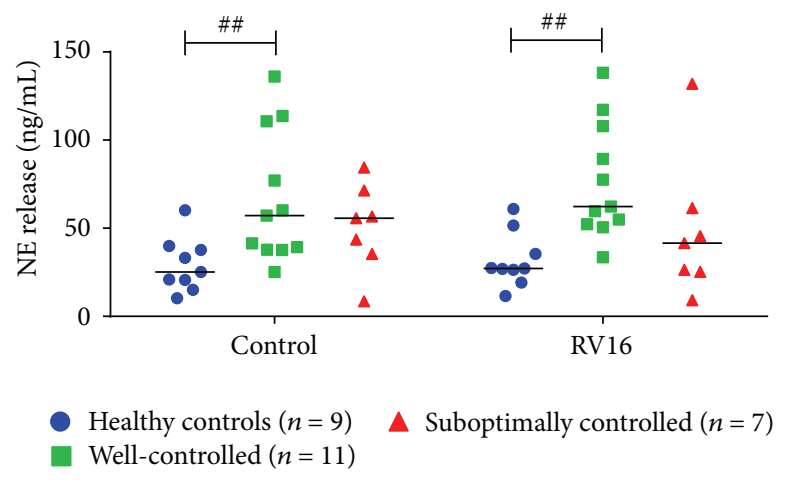

(c)

FIGURE 2: NE release from neutrophils stimulated with bacterial and viral mimetics and RV16. NE release from healthy controls (blue circles, $n=9$ ), well-controlled asthmatic (green squares, $n=11$ ), and suboptimally controlled asthmatic (red triangles, $n=7)$ neutrophils stimulated with (a) bacterial compounds: lipopolysaccharide (LPS), f-Met-Leu-Phe (fMLF), and DMSO (vehicle control), (b) viral surrogates: imiquimod, R848, and polyinosinic:polycytidylic acid (poly I:C), and (c) RV16 after 1 hour. Raw data is presented as a scatter plot with median. ${ }^{*} p<0.05$ compared to unstimulated control. ${ }^{\#} p<0.05,{ }^{\# \#} p<0.01$, and ${ }^{\# \# \#} p<0.001$ between indicated disease groups.

As airway epithelial cells and smooth muscle cells are fundamentally altered in asthma [21-24], even when grown for several cycles in vitro where they are deprived of altered signals in an asthmatic airway, we hypothesised that antimicrobial functions would similarly be dysfunctional in neutrophils from suboptimally controlled asthma. We hypothesised that there would be deficient immune responses in circulating neutrophils from people with suboptimally controlled asthma which potentially could lead to more severe or long lasting respiratory infections and ultimately an exacerbation. This study provides valuable and novel insights into circulating neutrophilic inflammatory responses.

In this study we were interested in investigating if neutrophils are already dysfunctional prior to entering the airway tissue in patients with asthma which could be intensified with altered inflammatory signals. As such, we chose to use peripheral blood neutrophils which we believe to be appropriate for investigation of possible differences in these cells. Since neutrophils are released into the circulation from the bone marrow we believe this cell population best reflects neutrophil function that has not had further differentiation signals provided during extravasation and in the airway lumen.
$\mathrm{RV}$ is a major precipitant of viral-induced exacerbations in asthma [8]. Neutrophils migrate into the airways during RV infections $[38,39]$ but their role in antiviral immunity remains unclear as is their ability to become infected with RV despite expressing ICAM-1 [40], the attachment protein for the serotype of RV used in this study. It is not clear why RV induced CXCL8 in this study. In the absence of replication we have previously shown that RV binding to ICAM-1 is sufficient to induce cytokine release in some [41] but not all lung cells [42]. Toll-like receptors (TLRs), particularly TLR 3, TLR 7, and TLR 8, detect viruses and usually their activation leads to typical innate activation. Potentially if RV is phagocytosed, TLR 3, TLR 7, and TLR 8 present on phagocytic vesicles may be activated. Alternatively cell surface TLR $3[43,44]$ may detect the presence of the virus.

Our finding that RV16 can induce CXCL8 in asthmatic neutrophils is novel, although the clinical relevance for the small induction observed here is questionable and needs to be interpreted with caution. However, the titre of RV in vivo is likely to be much higher than we used in vitro (reported $1000 \mathrm{TCID} / \mathrm{mL}$ in nasal lavage fluid [45]); therefore we speculate that a greater response to RV may occur in vivo. It is also plausible that patients with more severe disease are more sensitive to relatively small changes in inflammatory 


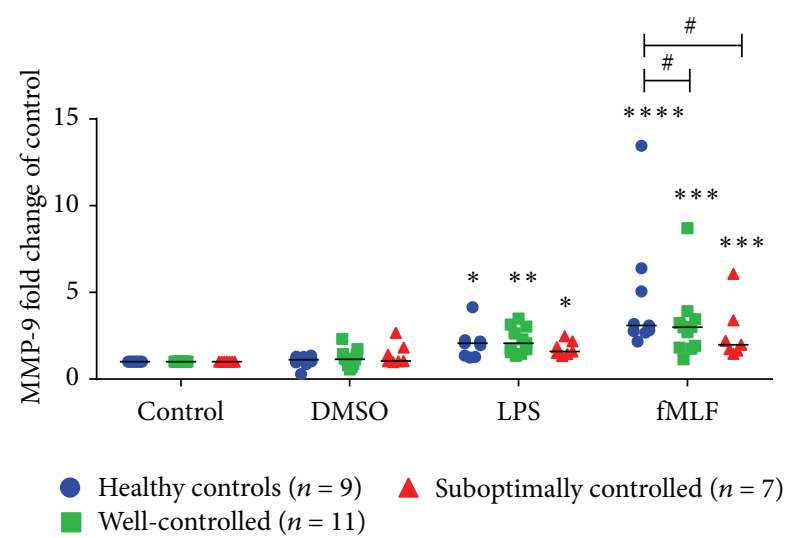

(a)

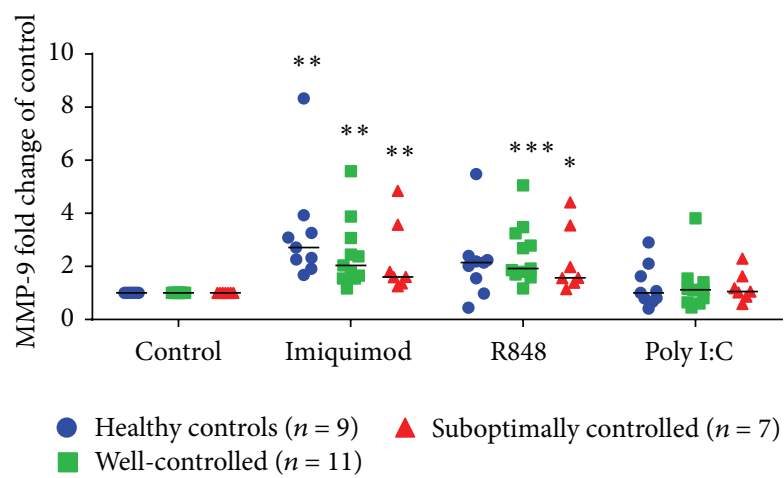

(b)

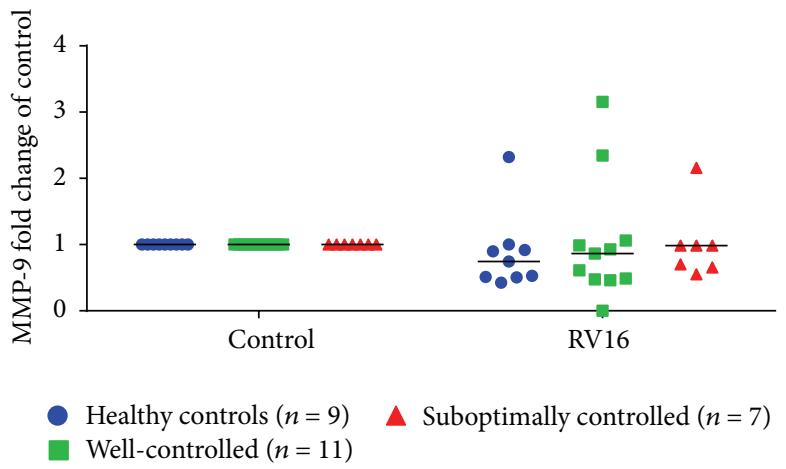

(c)

FIGURE 3: MMP-9 release from neutrophils stimulated with bacterial and viral mimetics and RV16. MMP-9 release from healthy controls (blue circles, $n=9$ ), well-controlled asthmatic (green squares, $n=11$ ), and suboptimally controlled asthmatic (red triangles, $n=7)$ neutrophils stimulated with (a) bacterial compounds: lipopolysaccharide (LPS), f-Met-Leu-Phe (fMLF), and DMSO (vehicle control), (b) viral surrogates: imiquimod, R848, and polyinosinic:polycytidylic acid (poly I:C), and (c) RV16 after 1 hour. Raw data is presented as a scatter plot with median. ${ }^{*} p<0.05,{ }^{* *} p<0.01,{ }^{* * *} p<0.001$, and ${ }^{* * * *} p<0.0001$ compared to unstimulated control. ${ }^{*} p<0.05$ between indicated disease groups.

cytokine production due to the cumulative effect of a greater number of neutrophils present. Dysregulation in CXCL8 induction by RV16 could play a role in the pathogenesis of asthma exacerbations and persistent airway neutrophilia but this requires further investigation.

fMLF, a bacterial derived protein and ligand for the fMLF receptor, stimulates neutrophils to migrate, produce inflammatory mediators, and release granules and reactive oxygen species [46]. We observed stimulant and disease specific changes in the response to fMLF. We believe these changes are not related to PMLF receptor expression since in the same patients with well-controlled asthma; fMLF induced CXCL8 release was approximately half the response of healthy controls but NE release was augmented.

NE and MMP-9 are both proteases and are found in neutrophil azurophil and gelatinase granules, respectively [47]. Like all proteases, tight regulation is required to ensure localisation of the enzymes to the area of infection; otherwise tissue damage can occur. We observed that, even under the same stimulation conditions, NE and MMP-9 release were differentially regulated, that is, a deficient fMLF induced MMP-9 response but an augmented fMLF induced NE response in neutrophils from well-controlled asthmatics.
This differential regulation could be due to the location of these products in different types of granules and their differing propensity to be released from neutrophils under certain stimulation conditions. However, further investigation of these mechanisms was outside the scope of this study and could be the subject for future studies.

Interestingly, we found similar neutrophil responses between patients with suboptimally controlled asthma and well-controlled asthma, particularly with deficient fMLF induced CXCL8 and MMP-9 release. Neutrophil function is known to decline with age and these changes include decreased phagocytic ability $[48,49]$, reduction in degranulation [50], and reduced capacity to generate reactive oxygen species [48]. In previous work we found that neutrophils from asthmatics with a mean age of 35 years had a greater propensity to release CXCL8 with R848 stimulation compared to nonasthmatic controls; however, other stimulants which included fMLF were similar between the two groups [25]. In this study where participants had a mean age of 62 years, we did not observe enhanced R848 induced CXCL8 from neutrophils, rather similar levels between both asthmatic groups and healthy controls. In addition, we noted deficient CXCL8 and MMP-9 release with PMLF stimulation which 


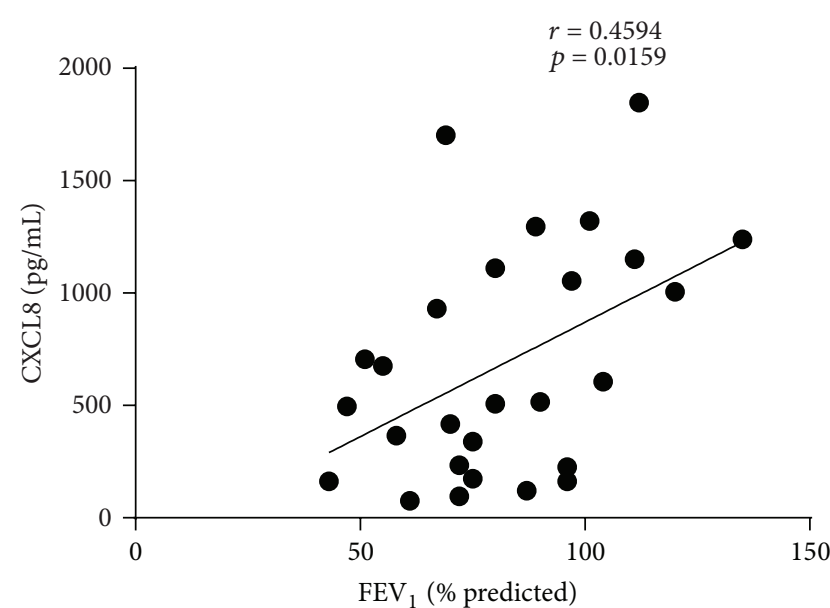

(a)

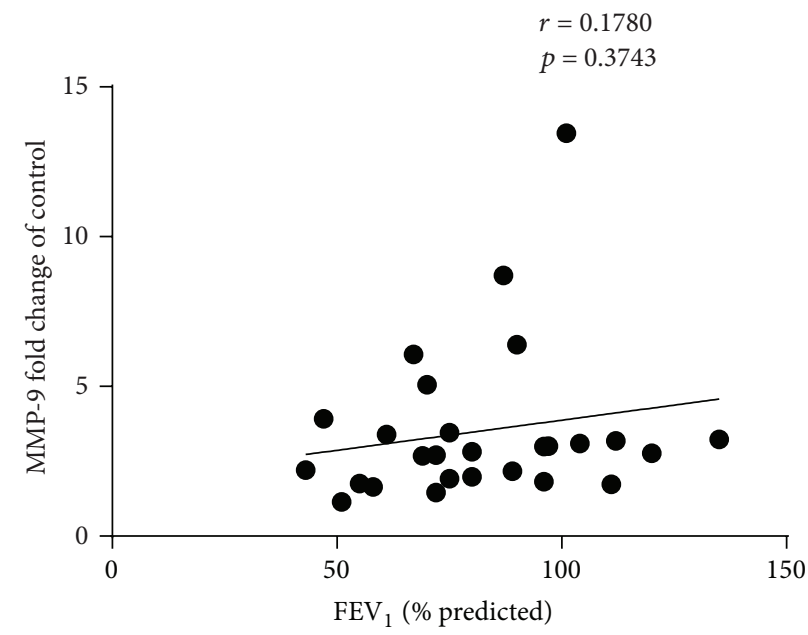

(c)

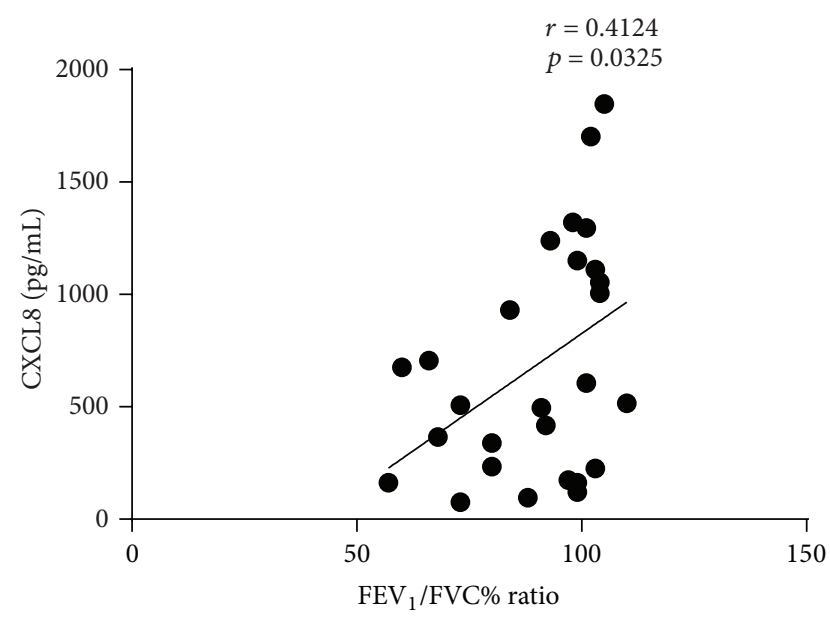

(b)

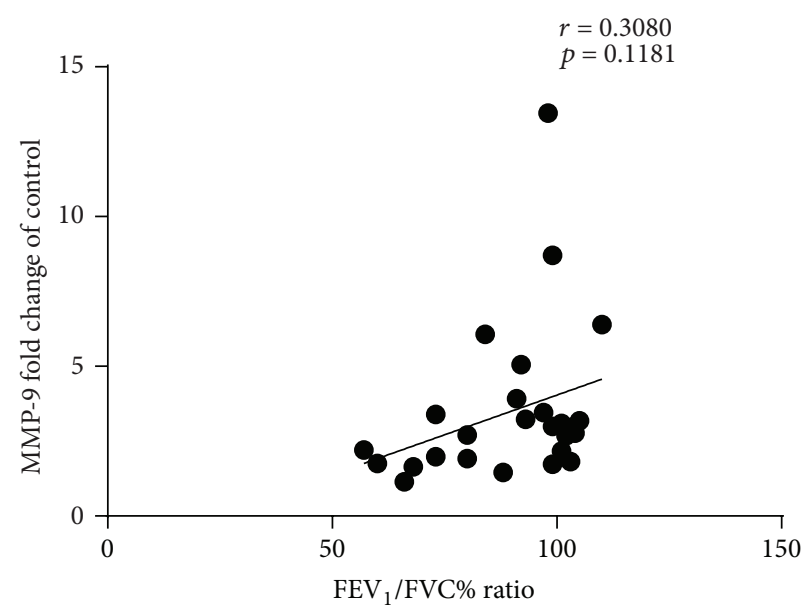

(d)

FIGURE 4: Correlation of $\mathrm{FEV}_{1}$ and $\mathrm{FEV}_{1} / \mathrm{FVC}$ with $\mathrm{fMLF}$ induced CXCL8 and MMP-9 from neutrophils. Correlations of fMLF induced (a-b) CXCL8 release and (c-d) MMP-9 with $\mathrm{FEV}_{1}(\mathrm{a}-\mathrm{c})$ and $\mathrm{FEV}_{1} / \mathrm{FVC}$ ratio (b-d).

may suggest that decline in neutrophil function is greater in those with disease, particularly in recognition of bacteria.

Studies have reported CXCL8 levels in the airways inversely correlate with $\mathrm{FEV}_{1}$ in asthmatic individuals $[3,51$, 52]. These studies measured CXCL8 in the bronchial alveolar lavage (BAL) and induced sputum which indicate the total inflammatory mediator load in the airways but give little indication of the source. In this study we found that basal CXCL8 release from neutrophils does not correlate with lung function, suggesting that neutrophils may not be the main source of this cytokine in BAL. However, fMLF induced CXCL8 positively correlated with both $\mathrm{FEV}_{1}$ and $\mathrm{FEV}_{1} / \mathrm{FVC}$. $\mathrm{fMLF}$ stimulates neutrophils via the FPR1 receptor. Interestingly annexin A1 also activates the $\mathrm{MLF}$ receptor [53]. As corticosteroid induced annexin A1 is a major antiinflammatory mechanism it is interesting to speculate that the responsiveness to $\mathrm{AMLF}$ may also indicate steroid insensitivity.

Our study has several limitations; the number of participants is small and the patients with suboptimal asthma control may have been quite heterogenous. Few participants had an ACQ > 1.5, which is the cut point used to be confident that asthma control is poor [30]. As we do not have eosinophil counts there is potential that the suboptimally controlled asthma group could contain steroid refractory eosinophilic asthmatics. These patients are distinct from neutrophilic refractory asthmatics as they have eosinophilia despite high dose steroid therapy and respond to anti-IL-5 antibody therapy $[54,55]$. Detailed phenotyping and endotyping of asthma are areas of interest to help personalise treatment options [56]. Our study is limited in this respect and future studies with larger population groups could address this question. It is also becoming clear that neutrophils are a nonhomogenous population of cells that carry out various functions ranging from the classical proinflammatory response to an immune modulatory response [57]. Investigation in this area was out of the scope of our study but would be of interest to closely investigate neutrophil subtypes in different asthmatic populations. 
In conclusion, no significant differences were seen in neutrophil function between patients with well- and suboptimally controlled asthma and therefore it is unlikely that neutrophil dysregulation drives asthma control. However, neutrophils from people with asthma appear to have different responses to pathogenic stimuli compared to healthy controls. This dysfunction may contribute to persistent or greater susceptibility to infection in asthmatics and is likely to be associated with airway obstruction.

$\begin{array}{ll}\text { Abbreviations } \\ \text { ACQ: } & \text { Asthma control questionnaire } \\ \text { BDP-HFA: } & \text { Beclometasone dipropionate } \\ & \text { (hydrofluoroalkane propellant) } \\ \text { CXCL8: } & \text { Interleukin } 8 \\ \text { FEV }: & \text { Forced expiratory volume in } 1 \text { second } \\ \text { fMLF: } & \text { f-Met-Leu-Phe } \\ \text { FVC: } & \text { Forced vital capacity } \\ \text { ICS: } & \text { Inhaled corticosteroid } \\ \text { LPS: } & \text { Lipopolysaccharide } \\ \text { MMP-9: } & \text { Matrix metalloproteinase-9 } \\ \text { NE: } & \text { Neutrophil elastase } \\ \text { RV: } & \text { Rhinovirus. }\end{array}$

\section{Ethical Approval}

This study was approved by Human Research Ethics Committee, The University of Sydney.

\section{Consent}

Written informed consent was obtained from all volunteers.

\section{Conflict of Interests}

The authors declared no conflict of interests regarding this paper.

\section{Authors' Contribution}

Francesca S. M. Tang, Peter G. Gibson, Gloria J. Foxley, Janette K. Burgess, Katherine J. Baines, and Brian G. Oliver provided conception and design of the project. Francesca S. M. Tang and Gloria J. Foxley carried out recruitment. Francesca S. M. Tang completed all cell biology, laboratory work, and data analysis. All authors contributed to the preparation of the paper.

\section{Acknowledgments}

This study was funded by the National Health and Medical Research Council (NHMRC), Australia. Janette K. Burgess was supported by a NHMRC Career Development Fellowship no. 1032695. Brian G. Oliver was supported by a NHMRC Career Development Fellowship no. 1026880.

\section{References}

[1] Australian Centre for Asthma Monitoring, Asthma in Australia 2011: With a Focus Chapter on Chronic Obstructive Pulmonary Disease, Asthma Series, 4(ACM 22), Australian Centre for Asthma Monitoring, 2011.

[2] A. Jatakanon, C. Uasuf, W. Maziak, S. Lim, K. F. Chung, and P. J. Barnes, "Neutrophilic inflammation in severe persistent asthma," American Journal of Respiratory and Critical Care Medicine, vol. 160, no. 5, pp. 1532-1539, 1999.

[3] K. Hosoki, S. Ying, C. Corrigan et al., "Analysis of a panel of 48 cytokines in BAL fluids specifically identifies IL-8 levels as the only cytokine that distinguishes controlled asthma from uncontrolled asthma, and correlates inversely with FEV1," PLoS ONE, vol. 10, no. 5, Article ID e0126035, 2015.

[4] R. R. L. Wener and E. H. Bel, "Severe refractory asthma: an update," European Respiratory Review, vol. 22, no. 129, pp. 227235,2013

[5] S. E. Wenzel, L. B. Schwartz, E. L. Langmack et al., "Evidence that severe asthma can be divided pathologically into two inflammatory subtypes with distinct physiologic and clinical characteristics," American Journal of Respiratory and Critical Care Medicine, vol. 160, no. 3, pp. 1001-1008, 1999.

[6] M. D. Eisner, P. P. Katz, E. H. Yelin, S. C. Shiboski, and P. D. Blanc, "Risk factors for hospitalization among adults with asthma: the influence of sociodemographic factors and asthma severity," Respiratory Research, vol. 2, no. 1, pp. 53-60, 2001.

[7] W. C. Moore, E. R. Bleecker, D. Curran-Everett et al., "Characterization of the severe asthma phenotype by the National Heart, Lung, and Blood Institute's Severe Asthma Research Program," Journal of Allergy and Clinical Immunology, vol. 119, no. 2, pp. 405-413, 2007.

[8] T. V. Grissell, H. Powell, D. R. Shafren et al., "Interleukin-10 gene expression in acute virus-induced asthma," American Journal of Respiratory and Critical Care Medicine, vol. 172, no. 4, pp. 433439, 2005.

[9] M. Iikura, M. Hojo, R. Koketsu et al., "The importance of bacterial and viral infections associated with adult asthma exacerbations in clinical practice," PLoS ONE, vol. 10, no. 4, Article ID e0123584, 2015.

[10] T. W. Clark, M.-J. Medina, S. Batham, M. D. Curran, S. Parmar, and K. G. Nicholson, "Adults hospitalised with acute respiratory illness rarely have detectable bacteria in the absence of COPD or pneumonia; viral infection predominates in a large prospective UK sample," Journal of Infection, vol. 69, no. 5, pp. 507-515, 2014.

[11] M. Kupczyk and S. Wenzel, "US and European severe asthma cohorts: what can they teach us about severe asthma?" Journal of Internal Medicine, vol. 272, no. 2, pp. 121-132, 2012.

[12] N. N. Jarjour, J. E. Gern, E. A. B. Kelly, C. A. Swenson, C. R. Dick, and W. W. Busse, "The effect of an experimental rhinovirus 16 infection on bronchial lavage neutrophils," Journal of Allergy and Clinical Immunology, vol. 105, no. 6, pp. 1169-1177, 2000.

[13] P. G. Gibson, J. L. Simpson, and N. Saltos, "Heterogeneity of airway inflammation in persistent asthma: Evidence of neutrophilic inflammation and increased sputum interleukin-8," Chest, vol. 119, no. 5, pp. 1329-1336, 2001.

[14] S. E. Wenzel, S. J. Szefler, D. Y. M. Leung, S. I. Sloan, M. D. Rex, and R. J. Martin, "Bronchoscopic evaluation of severe asthma," American Journal of Respiratory and Critical Care Medicine, vol. 156, no. 3, pp. 737-743, 1997.

[15] P. G. Woodruff, R. Khashayar, S. C. Lazarus et al., "Relationship between airway inflammation, hyperresponsiveness, and 
obstruction in asthma," Journal of Allergy and Clinical Immunology, vol. 108, no. 5, pp. 753-758, 2001.

[16] R. H. Green, C. E. Brightling, G. Woltmann, D. Parker, A. J. Wardlaw, and I. D. Pavord, "Analysis of induced sputum in adults with asthma: identification of subgroup with isolated sputum neutrophilia and poor response to inhaled corticosteroids," Thorax, vol. 57, no. 10, pp. 875-879, 2002.

[17] J. Shannon, P. Ernst, Y. Yamauchi et al., "Differences in airway cytokine profile in severe asthma compared to moderate asthma," Chest, vol. 133, no. 2, pp. 420-426, 2008.

[18] L. G. Wood, K. J. Baines, J. Fu, H. A. Scott, and P. G. Gibson, "The neutrophilic inflammatory phenotype is associated with systemic inflammation in asthma," Chest, vol. 142, no. 1, pp. 8693, 2012.

[19] S. E. Wenzel, S. Balzar, M. Cundall, and H. W. Chu, "Subepithelial basement membrane immunoreactivity for matrix metalloproteinase 9: association with asthma severity, neutrophilic inflammation, and wound repair," Journal of Allergy and Clinical Immunology, vol. 111, no. 6, pp. 1345-1352, 2003.

[20] J. Monteseirin, "Neutrophils and asthma," Journal of Investigational Allergology and Clinical, vol. 19, no. 5, pp. 340-354, 2009.

[21] R. Berair, F. Hollins, and C. Brightling, "Airway smooth muscle hypercontractility in asthma," Journal of Allergy, vol. 2013, Article ID 185971, 7 pages, 2013.

[22] B. N. Lambrecht and H. Hammad, "The airway epithelium in asthma," Nature Medicine, vol. 18, no. 5, pp. 684-692, 2012.

[23] S. T. Holgate, "The sentinel role of the airway epithelium in asthma pathogenesis," Immunological Reviews, vol. 242, no. 1, pp. 205-219, 2011.

[24] P. B. Noble, C. D. Pascoe, B. Lan et al., "Airway smooth muscle in asthma: linking contraction and mechanotransduction to disease pathogenesis and remodelling," Pulmonary Pharmacology and Therapeutics, vol. 29, no. 2, pp. 96-107, 2014.

[25] F. S. M. Tang, Ly. D. Van, K. Spann et al., "Differential neutrophil activation in viral infections: enhanced TLR-7/8-mediated CXCL8 release in asthma," Respirology, 2015.

[26] V. Naranbhai, B. P. Fairfax, S. Makino et al., "Genomic modulators of gene expression in human neutrophils," Nature Communications, vol. 6, article 7545, 2015.

[27] A. M. Mauer, J. W. Athens, H. Ashenbrucker, G. E. Cartwright, and M. M. Wintrobe, "Leukokinetic studies. II. A method for labeling granulocytes in vitro with radioactive diisopropylfluorophosphate $\left(\mathrm{DFP}^{32}\right)$," The Journal of Clinical Investigation, vol. 39, no. 9, pp. 1481-1486, 1960.

[28] S. H. Saverymuttu, A. M. Peters, A. Keshavarzian, H. J. Reavy, and J. P. Lavender, "The kinetics of ${ }^{111}$ Indium distribution following injection of ${ }^{111}$ Indium labelled autologous granulocytes in man," British Journal of Haematology, vol. 61, no. 4, pp. 675685, 1985.

[29] K. J. Baines, J. L. Simpson, R. J. Scott, and P. G. Gibson, "Immune responses of airway neutrophils are impaired in asthma," Experimental Lung Research, vol. 35, no. 7, pp. 554-569, 2009.

[30] E. F. Juniper, K. Svensson, A.-C. Mörk, and E. Ståhl, "Measurement properties and interpretation of three shortened versions of the asthma control questionnaire," Respiratory Medicine, vol. 99, no. 5, pp. 553-558, 2005.

[31] J. Pillay, V. M. Kamp, E. Van Hoffen et al., "A subset of neutrophils in human systemic inflammation inhibits $\mathrm{T}$ cell responses through Mac-1," The Journal of Clinical Investigation, vol. 122, no. 1, pp. 327-336, 2012.
[32] C. K. Wong, P. F. Y. Cheung, W. K. Ip, and C. W. K. Lam, "Intracellular signaling mechanisms regulating toll-like receptor-mediated activation of eosinophils," American Journal of Respiratory Cell and Molecular Biology, vol. 37, no. 1, pp. 85-96, 2007.

[33] A. Papi and S. L. Johnston, "Rhinovirus infection induces expression of its own receptor intercellular adhesion molecule 1 (ICAM-1) via increased NF- $\kappa$ B-mediated transcription," The Journal of Biological Chemistry, vol. 274, no. 14, pp. 9707-9720, 1999.

[34] J. S. Lefebvre, T. Lévesque, S. Picard et al., "Extra domain a of fibronectin primes leukotriene biosynthesis and stimulates neutrophil migration through activation of Toll-like receptor 4," Arthritis and Rheumatism, vol. 63, no. 6, pp. 1527-1533, 2011.

[35] D. Van Ly, M. De Pedro, P. James et al., "Inhibition of phosphodiesterase 4 modulates cytokine induction from toll like receptor activated, but not rhinovirus infected, primary human airway smooth muscle," Respiratory Research, vol. 14, article 127, 2013.

[36] L. M. Moir, H. Y. Ng, M. H. Poniris et al., "Doxycycline inhibits matrix metalloproteinase-2 secretion from TSC2-null mouse embryonic fibroblasts and lymphangioleiomyomatosis cells," British Journal of Pharmacology, vol. 164, no. 1, pp. 83-92, 2011.

[37] P. K. Correll, L. M. Poulos, R. Ampon, H. K. Reddel, and G. B. Marks, Respiratory Medication use in Australia 2003-2013: Treatment of Asthma and COPD. Cat. No. ACM 31, AIHW, Canberra, Australia, 2015.

[38] D. R. Nagarkar, Q. Wang, J. Shim et al., "CXCR2 is required for neutrophilic airway inflammation and hyperresponsiveness in a mouse model of human rhinovirus infection," The Journal of Immunology, vol. 183, no. 10, pp. 6698-6707, 2009.

[39] J. E. Gern, R. Vrtis, K. A. Grindle, C. Swenson, and W. W. Busse, "Relationship of upper and lower airway cytokines to outcome of experimental rhinovirus infection," American Journal of Respiratory and Critical Care Medicine, vol.162, no. 6, pp. 22262231, 2000.

[40] J. H. Wang, D. M. Sexton, H. P. Redmond, R. W. G. Watson, D. T. Croke, and D. Bouchier-Hayes, "Intercellular adhesion molecule-1 (ICAM-1) is expressed on human neutrophils and is essential for neutrophil adherence and aggregation," Shock, vol. 8, no. 5, pp. 357-361, 1997.

[41] B. G. G. Oliver, S. L. Johnston, M. Baraket et al., "Increased proinflammatory responses from asthmatic human airway smooth muscle cells in response to rhinovirus infection," Respiratory Research, vol. 7, article 71, 2006.

[42] B. G. G. Oliver, S. Lim, P. Wark et al., "Rhinovirus exposure impairs immune responses to bacterial products in human alveolar macrophages," Thorax, vol. 63, no. 6, pp. 519-525, 2008.

[43] M. Matsumoto, S. Kikkawa, M. Kohase, K. Miyake, and T. Seya, "Establishment of a monoclonal antibody against human Tolllike receptor 3 that blocks double-stranded RNA-mediated signaling," Biochemical and Biophysical Research Communications, vol. 293, no. 5, pp. 1364-1369, 2002.

[44] A. M. Lundberg, S. K. Drexler, C. Monaco et al., "Key differences in TLR3/poly I:C signaling and cytokine induction by human primary cells: a phenomenon absent from murine cell systems," Blood, vol. 110, no. 9, pp. 3245-3252, 2007.

[45] F. G. Hayden, R. B. Turner, J. M. Gwaltney et al., "Phase II, randomized, double-blind, placebo-controlled studies of ruprintrivir nasal spray 2-percent suspension for prevention and treatment of experimentally induced rhinovirus colds in healthy volunteers," Antimicrobial Agents and Chemotherapy, vol. 47, no. 12, pp. 3907-3916, 2003. 
[46] M. A. Panaro and V. Mitolo, "Cellular responses to FMLP challenging: a mini-review," Immunopharmacology and Immunotoxicology, vol. 21, no. 3, pp. 397-419, 1999.

[47] C. T. N. Pham, "Neutrophil serine proteases: specific regulators of inflammation," Nature Reviews Immunology, vol. 6, no. 7, pp. 541-550, 2006.

[48] C. Wenisch, S. Patruta, F. Daxböck, R. Krause, and W. Hörl, "Effect of age on human neutrophil function," Journal of Leukocyte Biology, vol. 67, no. 1, pp. 40-45, 2000.

[49] M. H. Crighton and A. A. Puppione, "Geriatric neutrophils: implications for older adults," Seminars in Oncology Nursing, vol. 22, no. 1, pp. 3-9, 2006.

[50] J. M. Lord, S. Butcher, V. Killampali, D. Lascelles, and M. Salmon, "Neutrophil ageing and immunesenescence," Mechanisms of Ageing and Development, vol. 122, no. 14, pp. 1521-1535, 2001.

[51] B. J. Green, S. Wiriyachaiporn, C. Grainge et al., "Potentially pathogenic airway bacteria and neutrophilic inflammation in treatment resistant severe asthma," PLoS ONE, vol. 9, no. 6, Article ID e100645, 2014.

[52] S. A. Little, K. J. MacLeod, G. W. Chalmers, J. G. Love, C. McSharry, and N. C. Thomson, "Association of forced expiratory volume with disease duration and sputum neutrophils in chronic asthma," The American Journal of Medicine, vol. 112, no. 6, pp. 446-452, 2002.

[53] G. Leoni, A. Alam, P. Alexander Neumann et al., "Annexin A1, formyl peptide receptor, and NOX1 orchestrate epithelial repair," Journal of Clinical Investigation, vol. 123, no. 1, pp. 443454, 2013.

[54] P. Nair, M. M. M. Pizzichini, M. Kjarsgaard et al., "Mepolizumab for prednisone-dependent asthma with sputum eosinophilia," The New England Journal of Medicine, vol. 360, no. 10, pp. 985993, 2009.

[55] I. D. Pavord, S. Korn, P. Howarth et al., "Mepolizumab for severe eosinophilic asthma (DREAM): a multicentre, double-blind, placebo-controlled trial," The Lancet, vol. 380, no. 9842, pp. 651659, 2012.

[56] I. Agache, C. Akdis, M. Jutel, and J. C. Virchow, "Untangling asthma phenotypes and endotypes," Allergy, vol. 67, no. 7, pp. 835-846, 2012.

[57] J. Pillay, T. Tak, V. M. Kamp, and L. Koenderman, "Immune suppression by neutrophils and granulocytic myeloid-derived suppressor cells: similarities and differences," Cellular and Molecular Life Sciences, vol. 70, no. 20, pp. 3813-3827, 2013. 


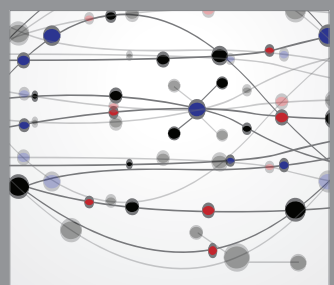

The Scientific World Journal
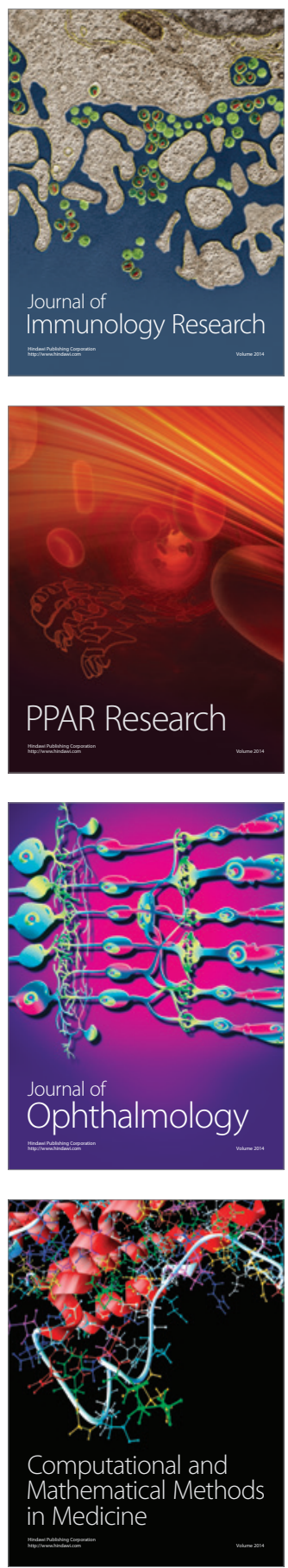

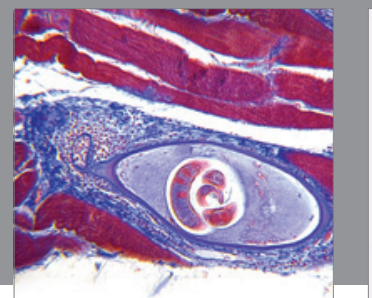

Gastroenterology

Research and Practice
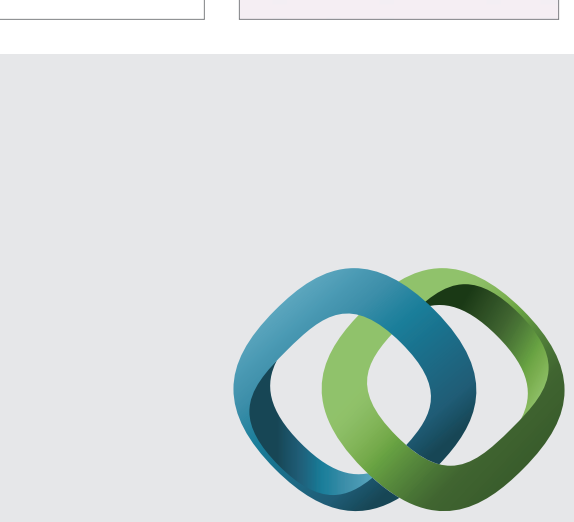

\section{Hindawi}

Submit your manuscripts at

http://www.hindawi.com
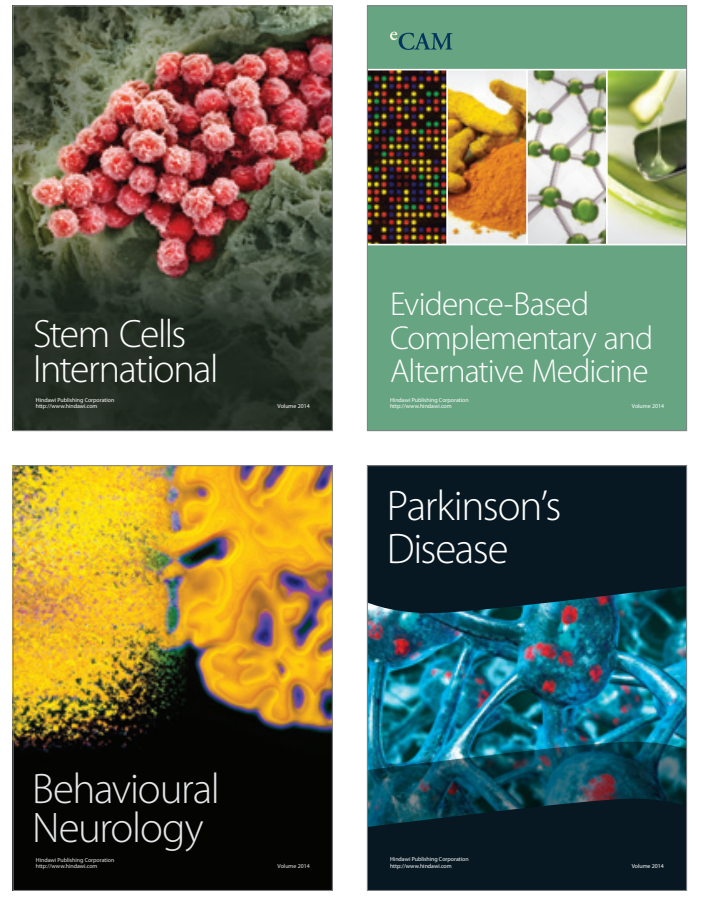
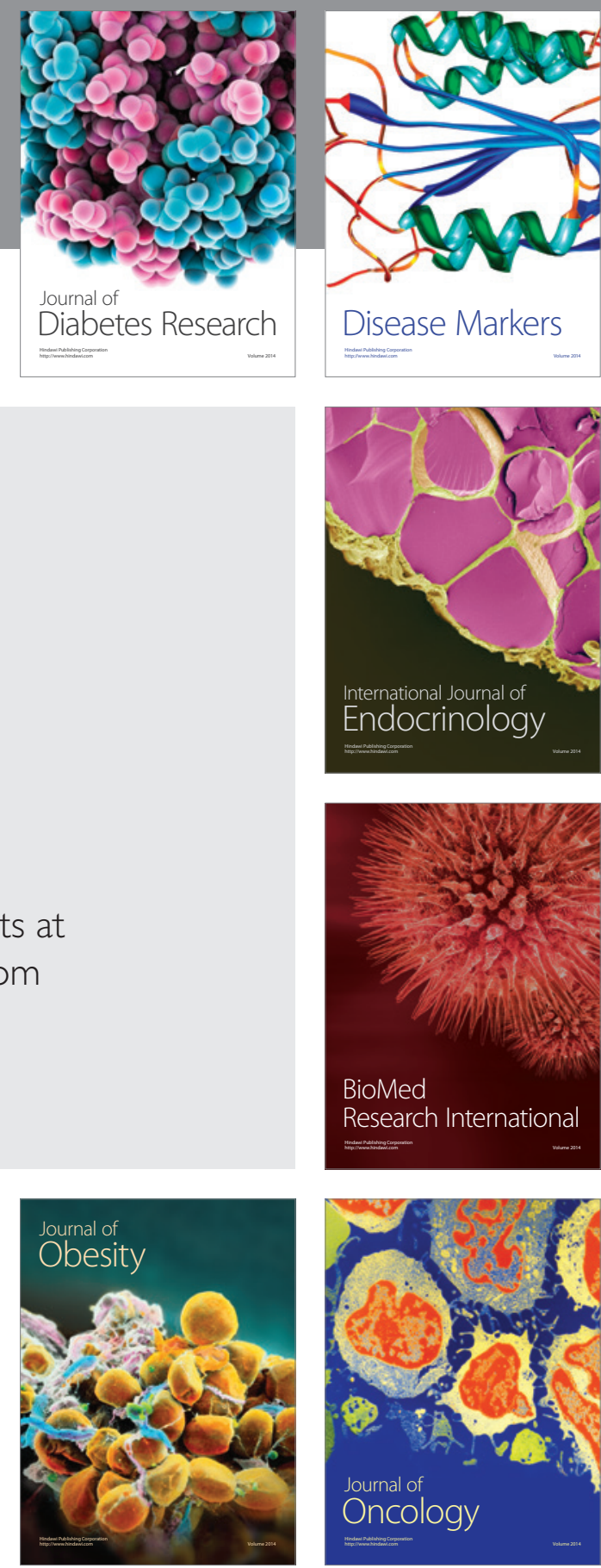

Disease Markers
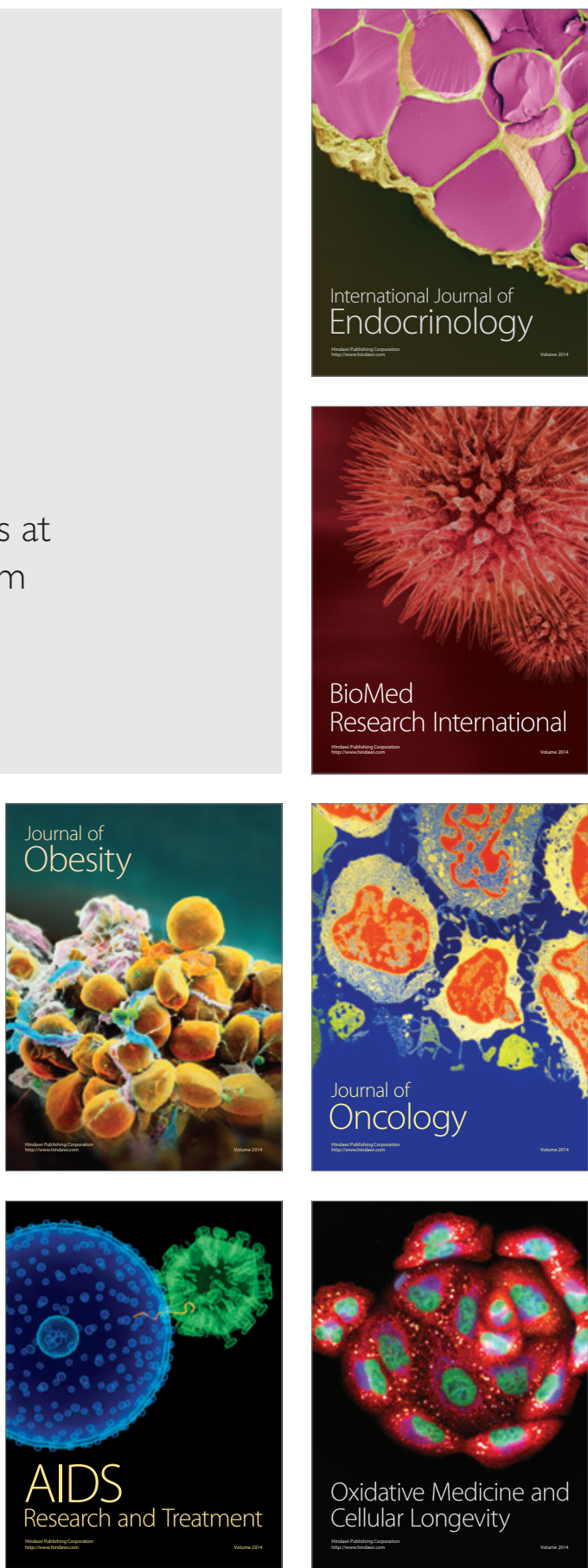